\title{
Comparison of micro-ultrasound and multiparametric magnetic resonance imaging for prostate cancer: A multicenter, prospective analysis
}

Laurence Klotz ${ }^{1}$; Giovanni Lughezzani ${ }^{2}$; Davide Maffei²; Andrea Sánchez ${ }^{3}$; José Gregorio Pereira $^{3}$; Frédéric Staerman ${ }^{4}$; Hannes Cash ${ }^{5}$; Ferdinand Luger ${ }^{6}$; Laurent Lopez ${ }^{7}$; Rafael SanchezSalas $^{8}$; Rob Abouassaly ${ }^{9}$; Neal D. Shore ${ }^{10}$; Gregg Eure ${ }^{11}$

Additional contributors:

Marco Paciotti ${ }^{2}$; Ander Astobieta ${ }^{3}$; Laura Wiemer ${ }^{5}$; Sebastian Hofbauer ${ }^{5}$; Robin Heckmann ${ }^{5}$; Andreas Gusenleitner ${ }^{6}$; Jasmin $\mathrm{Kaar}^{6}$; Clemens Mayr ${ }^{6}$; Wolfgang Loidl ${ }^{6}$; Jean Rouffilange ${ }^{7}$; Richard Gaston $^{7}$; Xavier Cathelineau ${ }^{8}$; Eric Klein ${ }^{9}$

${ }^{1}$ Sunnybrook Hospital, Toronto, ON, Canada; ${ }^{2}$ Instituto Clinico Humanitas, Rozzano, Italy; ${ }^{3}$ Urología Clínica, Clínica IMQ Zorrotzaurre, Spain; ${ }^{4}$ Polyclinique Reims-Bezannes, Bezannes, France; ${ }^{5}$ Charité Universitätsmedizin Berlin, Berlin, Germany; ${ }^{6}$ Ordensklinikum Linz, Barmherzige Schwestern Linz, Austria; ${ }^{7}$ Groupe Urologie SaintAugustin, Bordeaux, France; ${ }^{8}$ Institut Mutualiste Montsouris, Paris, France; ${ }^{9}$ Glickman Urological Institute, Cleveland Clinic, Cleveland, OH, United States; ${ }^{10}$ Carolina Urologic Research Center, Myrtle Beach, SC, United States; ${ }^{11}$ Urology of Virginia, Virginia Beach, VA, United States

Acknowledgement/Funding: The Terry Fox Foundation provided funding for the Sunnybrook ExactVue imaging system. The authors would like to thank Brian Wodlinger for management of the registry and statistical assistance This registry was provided by Exact Imaging, Toronto Canada; Statistical support was provided by Brian Wodlinger, Exact Imaging, Toronto, ON, Canada.

Cite as: Can Urol Assoc J 2020 July 17; Epub ahead of print. http://dx.doi.org/10.5489/cuaj.6712 Published online July 17, 2020

$* * *$

\section{Abstract}

Introduction: High-resolution micro-ultrasound has the capability of imaging prostate cancer based on detecting alterations in ductal anatomy, analogous to multiparametric magnetic resonance imaging (mpMRI). This technology has the potential advantages of relatively low cost, simplicity, and accessibility compared to mpMRI. This multicenter, prospective registry aims to compare the sensitivity, specificity, negative predictive value (NPV), and positive predictive value (PPV) of mpMRI with high-resolution micro-ultrasound imaging for the detection of clinically significant prostate cancer.

Methods: We included 1040 subjects at 11 sites in seven countries who had prior mpMRI and underwent ExactVu micro-ultrasound-guided biopsy. Biopsies were taken from both mpMRI 
targets (PI-RADS >3 and micro-ultrasound targets (PRIMUS >3). Systematic biopsies (up to 14 cores) were also performed. Various strategies were used for mpMRI target sampling, including cognitive fusion with micro-ultrasound, separate software-fusion systems, and software-fusion using the micro-ultrasound FusionVu system. Clinically significant cancer was those with Gleason grade group $\geq 2$.

Results: Overall, 39.5\% were positive for clinically significant prostate cancer. Microultrasound and mpMRI sensitivity was $94 \%$ vs. $90 \%$, respectively $(\mathrm{p}=0.03)$, and NPV was $85 \%$ vs. $77 \%$, respectively. Specificities of micro-ultrasound and MRI were both $22 \%$, with similar PPV (44\% vs. 43\%). This represents the initial experience with the technology at most of the participating sites and, therefore, incorporates a learning curve. Number of cores, diagnostic strategy, blinding to MRI results, and experience varied between sites.

Conclusions: In this initial multicenter registry, micro-ultrasound had comparable or higher sensitivity for clinically significant prostate cancer compared to mpMRI, with similar specificity. Micro-ultrasound is a low-cost, single-session option for prostate screening and targeted biopsy. Further larger-scale studies are required for validation of these findings.

\section{Introduction}

About $15 \%$ of men will be diagnosed with prostate cancer at some point during their lifetime. ${ }^{1}$ While mortality has improved substantially, attributed to early detection and improved treatment, it remains the second leading cause of cancer death in men. ${ }^{2}$ Accurate biopsy derived histopathology is a key determinant in treatment selection along with patient-physician shared decision making. ${ }^{3}$ Most men with localized, low risk disease are managed via active surveillance, while those with localized, higher risk disease are treated with surgery, radiation, or focal therapy regimens. ${ }^{3}$ Accurate biopsy techniques are crucial for determining the optimal treatment path for each patient.

Historically, prostate cancer diagnosis has been predicated upon TRUS guided systematic biopsies initiated due to PSA abnormal values and/or an abnormal prostate exam. The limitations of this approach are a high rate of clinically insignificant cancers, especially when performed solely for PSA abnormalities, as well as the potential for missing clinically significant cancer in $25-30 \%$ of biopsied patients. ${ }^{4}$

Recent randomized studies have demonstrated the superiority of mpMRI guided targeted biopsies in correctly identifying clinically significant cancer and reducing the rate of diagnosis of insignificant cancer. ${ }^{4-6}$ The European Association of Urology (EAU) currently recommends mpMRI imaging prior to all prostate biopsies, with the caveat that systematic biopsy is acceptable if mpMRI is unavailable. ${ }^{7}$ The National Comprehensive Cancer Network (NCCN) recommends MRI-assisted biopsy for patients with a prior negative systematic biopsy and 
clinical suspicion of cancer. ${ }^{8}$ This poses many challenges in terms of access, cost, and expertise.

High resolution $29 \mathrm{MHz}$ micro-ultrasound, a novel imaging modality, aims to improve the diagnostic accuracy of prostate biopsy while maintaining the affordability and convenience of ultrasound. Micro-ultrasound operates at $29 \mathrm{MHz}$, compared to traditional ultrasound systems that operate at frequencies of 6-9MHz. ${ }^{9}$ The axial resolution is improved from $200 \mu \mathrm{m}$ with conventional ultrasound to $<70 \mu \mathrm{m}$ with micro-ultrasound with a similar improvement in lateral resolution due to $90 \mu \mathrm{m}$ crystal spacing. This resolution is approximately the diameter of a prostatic duct and allows for the visualization of subtle changes in ductal anatomy associated with cancer. Diffusion-weighted imaging (DWI) is based upon measuring the random Brownian motion of water molecules within a voxel of tissue. Highly cellular tissues exhibit lower diffusion coefficients. Both technologies thus identify changes associated with high grade cancer. Real-time targeted biopsy can be performed, avoiding the need for a $2^{\text {nd }}$ procedure. A grading system, PRI-MUS, analogous to the PI-RADS system ${ }^{10}$, has been developed to stratify micro ultrasound images according to the risk of significant cancer.

This study sought to compare the sensitivity, specificity, NPV and PPV of mpMRI with highresolution micro-ultrasound in patients referred for biopsy who had a prior MRI.

\section{Methods}

This was a prospective registry which includes data from 11 urological centers in 7 countries in North America and Europe. All sites have well established prostate mpMRI programs with uroradiologists with at least 5 years of experience interpreting prostate MRI. The urologists had at least 5 years' experience performing TRUS prostate biopsy. It represents the initial 'real-life' experience with micro-ultrasound from those centres which were early adopters of the technology.

\section{Inclusion and exclusion criteria}

Broad inclusion criteria were used to provide a real-world analysis in the clinical population of men presenting for biopsy. This includes men with suspected prostate cancer based on elevated prostate-specific antigen (PSA) and/or abnormal digital rectal examination (DRE), with or without a suspicious mpMRI. A targeted biopsy procedure was performed for each subject, which included taking 2-3 cores from each mpMRI and micro-ultrasound target, as well as 12-14 systematic samples. A total of 1040 subjects were included in this analysis. Men were excluded if no mpMRI was performed prior to biopsy, no biopsy was performed, or biopsy was performed without sampling either modality's targets. 


\section{Analysis}

At all sites, 2-3 targeted samples from each target were taken for PI-RADS $\geq 3$ or PRI-MUS ${ }^{11} \geq$ 3 lesions. If the same site was identified on both modalities, this was biopsied using U/S guidance. In most cases, targeted biopsies (from both MRI and U/S identified abnormalities) were performed initially, followed by systematic biopsies. From the resultant pathology, clinically significant cancer was considered any $\mathrm{GG} \geq 2$. Patient-level sensitivities, specificities, positive predictive values, and negative predictive values were assessed for both microultrasound and mpMRI, combined across all sites as well as individually.

The primary endpoint of this registry was to determine patient-level sensitivity and specificity of each imaging modality to predict which men harbored significant prostate cancer. The benefit of MRI over systematic biopsy is about a $15 \%$ increase in the diagnosis of significant cancer. In this post hoc analysis, we hypothesized that the lower 2.5 th percentile of the difference between micro-ultrasound and mpMRI for GG $\geq 2$ PCa detection was greater than $-7.5 \%$, which maintains at least $50 \%$ of the benefit of MRI. Confidence Intervals were calculated using the Jefferys technique with exact calculation of difference p-values. ${ }^{12}$

\section{Results}

1040 patients were included with median age 67 (IQR 61-72) and PSA 7 ng/mL (5.1-10). Table 1 summarizes the demographics of the group. $22 \%$ of the patients had a palpable lesion on DRE. 16\% of ultrasound evaluations were non-suspicious (PRI-MUS 1-2), while $17 \%$ had an equivocal lesion (PRI-MUS 3) and 66\% were suspicious or highly suspicious (PRI-MUS 4-5). Table 2 lists the sites, indication for biopsy, mpMRI specifications, the fusion targeting system, and whether the ultrasound was performed blinded to the MRI. Most sites used clinical variables including MRI as the indication; one site only biopsied patients whose MRI showed a region of interest. 7 of the 11 sites used cognitive fusion; 4 sites used a fusion targeting system. 9 of the 11 sites were unblinded to the results of the MRI when the ultrasound was performed; 2 were blinded.

Of the 1040 MRIs, 864 were positive (83\%); of these, 364 (43\%) showed significant cancer. 40 of 1040 patients (4\%) had a negative MRI with significant cancer on biopsy. The false positive rate was $47 \%$. 877 of 1040 (84\%) had an ROI on micro-ultrasound; 25 had a negative micro-ultrasound with significant cancer on biopsy $(2 \%)$. The false positive rate of micro-ultrasound was $47 \%$. Positive predictive values were similar between MRI and MicroUltrasound and varied with risk score. PI-RADS 3 lesions were positive for csPCa in $14 \%$ (17/124) cases, while PI-RADS 4 were positive in 38\% (132/351). PI-RADS 5 lesions were positive for csPCa in $62 \%$ (120/193) of cases. PI-RADS scores were not available in 184 cases, with $91 \mathrm{csPCa}(46 \%)$.

Prostate cancer was identified in $61 \%$ of patients (632/1040), Grade Group 2 or higher prostate cancer in 39\% (411/1040) of patients, and Grade Group 3 or higher in 19\% (154/803) of 
patients. Sites A and I did not differentiate between GG2 and GG3 cases and were not included in assessments of GG3 or higher cancer. Significant variability in biopsy indication was evident between the enrolling centers, however the resulting sensitivity difference of MRI and microultrasound was consistent (Figure 1 and Table 3). Overall, micro-ultrasound demonstrated a sensitivity of $94 \%$ (386/411) for predicting GG $\geq 2$ PCa while mpMRI demonstrated a lower sensitivity of $90 \%(371 / 411)(\mathrm{p}=0.03)$. Specificity was similar at $22 \%(138 / 629)$ for microultrasound and 23\% (136/629) for mpMRI ( $<<0.01$ for non-inferiority) (Table 2).

Figure 1 shows a Forest plot of sensitivity by site. This was relatively consistent between sites, whether blinded or not. The overall sensitivity of micro-ultrasound was $3.6 \%$ higher than MRI, and the $\mathrm{p}$ value for non-inferiority was $<0.001$, and for superiority 0.03 . Figure 2 shows the Forest plot of specificity. There was substantial variation between sites. Micro-Ultrasound specificity was $0.3 \%$ higher than MRI with $\mathrm{p}<0.001$ for non-inferiority, and $\mathrm{p}=0.45$ for superiority.

All but 3 groups (all with $<65$ subjects) performed within the non-inferiority margin individually, suggesting robust inter-site performance. A sensitivity analysis was further conducted by removing each of the groups in order to determine whether the overall conclusion still held. P-values for non-inferiority were consistently significant for both sensitivity and specificity ( $<0.001-0.025$ for both). Superiority p-values varied considerably for specificity as expected given the widely varying performances between sites $(0.01-0.73)$, however sensitivity was consistently superior $(<0.01$ in all cases).

\section{Discussion}

The advent of prostate cancer imaging with mpMRI has dramatically altered the approach to prostate cancer diagnosis. Targeted biopsies result in more significant cancer and less insignificant cancer being diagnosed.

However, mpMRI has a number of limitations. It is a relatively expensive technology, there is a significant educational learning curve, and involves a second visit for the fusion targeted biopsy. There is potential toxicity associated with Gadolinium. mpMRI misses about $15 \%$ of significant cancers. ${ }^{13,14}$ Many care management facilities globally face challenges in providing access to MRI for all patients in whom it is indicated. Further, MRI interpretation is complex and subject to variability. In a study of the concordance by expert GU radiologists, the kappa for peripheral zone prostate lesions was only $0.59 .^{15}$ Fusion targeting introduces another potential source of error, whether performed cognitively or with an additional fusion biopsy system. Some men have a relative or absolute contraindication to MRI, including claustrophobia, prosthetic implants, pacemakers, or renal failure precluding gadolinium. ${ }^{16}$ Modifications to MRI, including the use of bi-parametric MRI, will address some of these issues, including gadolinium related toxicity and cost. ${ }^{17}$ 
High resolution micro-ultrasound offers the benefit of a comparatively inexpensive, simple technology, with imaging and biopsy performed as a single procedure. It does not require contrast. Ultrasound skills are widely diffused in the urological and radiological community, and the learning curve for micro-ultrasound imaging appears to be short In one study, the AUC flattened after 15 cases. ${ }^{18}$ The capital cost of the device is similar to other high-end ultrasound machines or MRI/US fusion devices, a fraction of the capital cost of MRI. The footprint is similar to conventional ultrasound. The only patients in whom the procedure is not possible are those with anal stenosis or absence post abdominal perineal resection.

The sensitivity of micro-ultrasound in this registry for significant prostate cancer was superior to MRI. The specificity trended non-significantly below that of MRI. The specificity likely is strongly related to the learning curve. Acquiring the confidence to exclude certain borderline abnormalities takes more experience identifying abnormalities. It is likely that with further experience and validation, the specificity will improve.

Limitations of the study: This was a 'real world' registry in 11 centers in 7 countries of a new technology. Thus, the results incorporate learning curves and significant variability between centers. Data was collected prospectively, but there was not a uniform protocol. Details of the methodologic variation between sites are listed in the supplementary table. Conventional 12 core systematic biopsies were not performed in most patients due to the inclusion of microultrasound targets within the systematic samples and adjustment of systematic positions to reflect tissue variations observed on micro-ultrasound. Thus the performance of micro ultrasound compared to systematic biopsies could not be determined. Variation in the approach to borderline lesions was substantial. For example, site A targeted all borderline lesions comprehensively, and achieved a high sensitivity at the expense of specificity. Site $\mathrm{C}$ did not enroll or schedule patients for biopsy unless they had a visible lesion on MRI, potentially missing MRI negative micro-US positive cases. Despite this, the sensitivity at their site was $94 \%$ compared to MRI. The number of cores per target was not standardized. Seven of the 11 sites were unblinded to the MRI when the ultrasound was performed, introducing an important source of bias in the interpretation of the ultrasound. However, results between the blinded and unblinded sites was similar. Only men with a prior mpMRI undergoing biopsy were enrolled, and data on patients who were excluded due no prior MRI was not available for comparison. Current studies where the ultrasound annotation is performed blinded to the MRI are ongoing. This was a comparison to mpMRI, without a gold standard of surgical pathology; therefore the known inaccuracies of biopsy grading could not be avoided. The PRI-MUS system used for ultrasound grading has not been validated.

\section{Conclusions}

This registry, the first large scale analysis of the initial multi-centre experience with microultrasound, has demonstrated comparable metrics to mpMRI with respect to sensitivity, 
specificity, NPV and PPV. This technology is an appealing alternative to MRI in the initial evaluation of men at risk for prostate cancer. Further studies are warranted to further validate this technology. 


\section{References}

1. National Cancer Institute. Cancer Stat Facts: Prostate Cancer. https://seer.cancer.gov/statfacts/html/prost.html. Accessed June 1, 2020.

2. Centers for Disease Control and Prevention. U.S. Cancer Statistics Data Visualizations Tool. https://www.cdc.gov/cancer/uscs/dataviz/index.htm. Accessed June 1, 2020.

3. National Comprehensive Cancer Network. Clinical Practice Guidelines in Oncology: Prostate Cancer. 2019; Version 4. https://www.nccn.org/professionals/physician_gls/pdf/prostate.pdf.

4. Rouvière $\mathrm{O}$, Puech $\mathrm{P}$, Renard-Penna R, et al. Use of prostate systematic and targeted biopsy on the basis of multiparametric MRI in biopsy-naive patients (MRI-FIRST): a prospective, multicentre, paired diagnostic study. Lancet Oncol. 2018;2045(18):1-10. doi:10.1016/S1470-2045(18)30569-2

5. Kasivisvanathan V, Rannikko AS, Borghi M, et al. MRI-Targeted or Standard Biopsy for Prostate-Cancer Diagnosis. N Engl J Med. 2018:NEJMoa1801993. doi:10.1056/NEJMoa1801993

6. Ahmed HU, El-Shater Bosaily A, Brown LC, et al. Diagnostic accuracy of multiparametric MRI and TRUS biopsy in prostate cancer (PROMIS): a paired validating confirmatory study. Lancet. 2017;6736(16):1-8. doi:10.1016/S0140-6736(16)32401-1

7. Mottet N, Cornford P, van den Bergh RCN, et al. EAU Guidelines: Prostate Cancer. In: EAU Annual Congress. Amsterdam: EAU Guidelines Office, Arnhem, The Netherlands.; 2020.

8. NCCN Clinical Practice Guidelines in Oncology V1.2019. Prostate Cancer Early Detection Recommendations. Natl Compr Cancer Network, Inc. 2019. https://www.nccn.org/professionals/physician_gls/pdf/prostate_detection.pdf.

9. Rohrbach D, Wodlinger B, Wen J, Mamou J, Feleppa E. High-Frequency Quantitative Ultrasound for Imaging Prostate Cancer Using a Novel Micro-Ultrasound Scanner. Ultrasound Med Biol. 2018. doi:10.1016/j.ultrasmedbio.2018.02.014

10. Turkbey B, Choyke PL. Pirads 2.0: What is new? Diagnostic Interv Radiol. 2015;21(5):382-384. doi:10.5152/dir.2015.15099

11. Ghai S, Eure G, Fradet V, et al. Assessing Cancer Risk on Novel 29 MHz MicroUltrasound Images of the Prostate: Creation of the Micro-Ultrasound Protocol for Prostate Risk Identification. J Urol. 2016;196(2):562-569. doi:10.1016/j.juro.2015.12.093

12. Brown LD, Cai TT, DasGupta A. Interval Estimation for a Binomial Proportion. Stat Sci. 2001;16(2):101-133. doi:10.1214/ss/1009213286

13. Stabile A, Giganti F, Emberton M, Moore CM. MRI in prostate cancer diagnosis: do we need to add standard sampling? A review of the last 5 years. Prostate Cancer Prostatic Dis. 2018;21(4):473-487. doi:10.1038/s41391-018-0071-8

14. Padhani AR, Haider MA, Villers A, Barentsz JO. Multiparametric Magnetic Resonance Imaging for Prostate Cancer Detection : What We See and What We Miss. Eur Urol. 2018:0-1. doi:10.1016/j.eururo.2018.12.004

15. Rosenkrantz AB, Ginocchio LA, Cornfeld D, et al. Interobserver Reproducibility of the 
PI-RADS Version 2 Lexicon: A Multicenter Study of Six Experienced Prostate Radiologists. Radiology. 2016;280(3):793-804. doi:10.1148/radiol.2016152542

16. Layne KA, Dargan PI, Archer JRH, Wood DM. Gadolinium deposition and the potential for toxicological sequelae - A literature review of issues surrounding gadolinium-based contrast agents. Br J Clin Pharmacol. 2018;84(11):2522-2534. doi:10.1111/bcp.13718

17. Porter KK, King A, Galgano SJ, Sherrer RL, Gordetsky JB, Rais-Bahrami S. Financial implications of biparametric prostate MRI. Prostate Cancer Prostatic Dis. 2020;23(1):88-93. doi:10.1038/s41391-019-0158-x

18. Hyndman M, Pavlovich C, Eure G, Fradet V, Ghai S. Prospective validation of PRIMUS $^{\mathrm{TM}}$, the Prostate Risk Identification using Micro-Ultrasound protocol for real-time detection of prostate cancer using high-resolution micro-ultrasound imaging. In: American Urology Association. San Francisco, USA; 2018. 
Figures and Tables

Fig 1. Forest plot demonstrating site-level sensitivity difference between micro-ultrasound and multiparametric magnetic resonance imaging. Sensitivity difference overall was $+3.6 \%$ indicating superior sensitivity for micro-ultrasound ( $\mathrm{p}=0.03$ ). CI: confidence interval.

Study
A
B
C
D
E
F
G
H
I
J
K
Overall effect
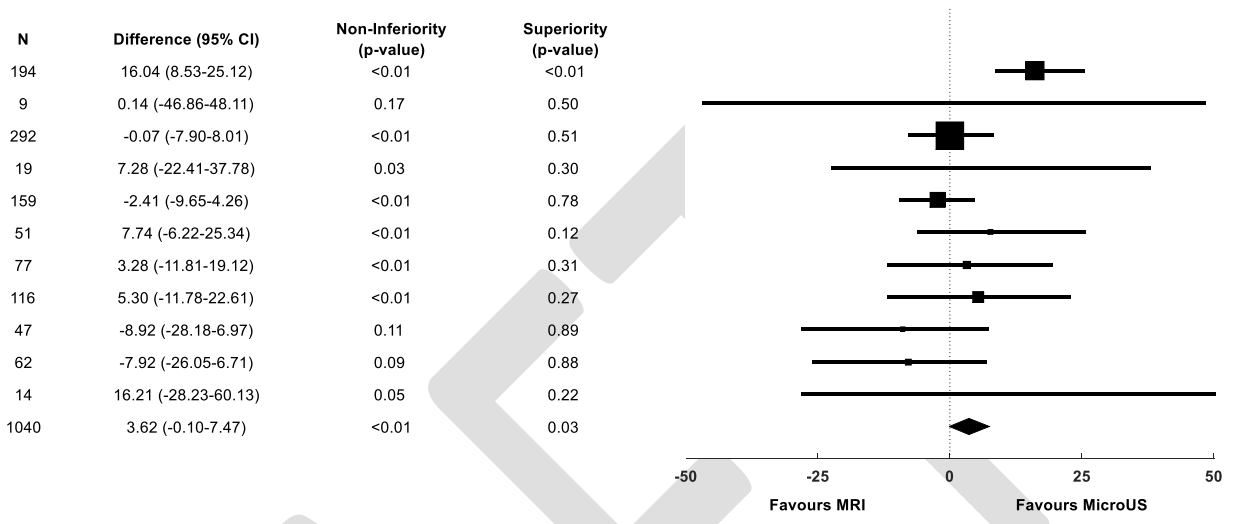

Fig. 2. Forest plot demonstrating site-level specificity difference between micro-ultrasound and multiparametric magnetic resonance imaging. Specificity difference was $+0.3 \%$ overall, indicating non-inferiority for micro-ultrasound $(\mathrm{p}<0.01)$, however, significant variability was noted between sites depending on biopsy population and user targeting habits. CI: confidence interval.

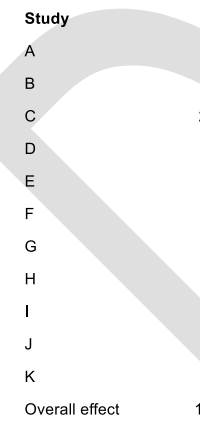

$$
\begin{gathered}
\text { Difference }(95 \% \mathrm{Cl}) \\
-29.52(-40.48-18.60) \\
-11.93(-49.12-23.95) \\
11.67(4.06-19.48) \\
-51.34(-81.81--11.38) \\
8.37(-0.98-18.24) \\
-13.06(-34.17-8.54) \\
-7.60(-23.33-8.47) \\
-3.54(-18.18-10.96) \\
16.52(-4.20-36.51) \\
46.80(30.24-62.10) \\
-16.13(-45.82-10.08) \\
0.28(-4.37-4.85)
\end{gathered}
$$

$\begin{array}{cc}\begin{array}{c}\text { Non-Inferiority } \\ \text { (p-value) } \\ <0.01\end{array} & \begin{array}{c}\text { Superiority } \\ \text { ( } \boldsymbol{p} \text {-value) } \\ 1.00\end{array} \\ 0.02 & 0.76 \\ <0.01 & <0.01 \\ 0.53 & 0.99 \\ <0.01 & 0.04 \\ <0.01 & 0.89 \\ <0.01 & 0.83 \\ <0.01 & 0.69 \\ <0.01 & 0.06 \\ <0.01 & <0.01 \\ 0.01 & 0.90 \\ <0.01 & 0.45\end{array}$

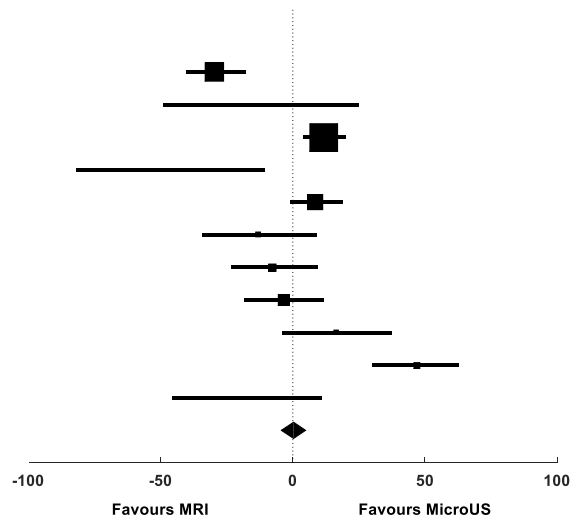




\begin{tabular}{|l|c|}
\hline \multicolumn{2}{|l|}{ Table 1. Patient demographics } \\
\hline & Overall \\
\hline N & 1040 \\
\hline Age, median (IQR) & $67(61-72)$ \\
\hline PSA, median (IQR) & $7(5.1-10)$ \\
\hline DRE (positive) & $208(128 \mathrm{NA})$ \\
\hline Prostate volume (mL), median (IQR) & $38(28-53)$ \\
\hline Prior biopsy (positive/total) & $66 / 352(281 \mathrm{NA})$ \\
\hline Percentage equivocal imaging (PRI-MUS 3) & $17 \%$ \\
\hline Percentage equivocal imaging (PI-RADS 3) & $19 \%$ \\
\hline
\end{tabular}

DRE: digital rectal exam; IQR: interquartile range; PSA: prostate-specific antigen.

\begin{tabular}{|c|c|c|c|c|c|}
\hline \multicolumn{6}{|c|}{ A. For detection of GG $\geq 2$ PCa (39\% of cases) } \\
\hline Modality & Sensitivity & Specificity & & PPV & NPV \\
\hline mpMRI & $\begin{array}{c}90 \% \\
(371 / 411)\end{array}$ & $\begin{array}{c}22 \% \\
(136 / 629)\end{array}$ & & $\begin{array}{c}43 \% \\
(371 / 864)\end{array}$ & $\begin{array}{c}77 \% \\
(136 / 176)\end{array}$ \\
\hline Micro-ultrasound & $\begin{array}{c}94 \% \\
(386 / 411)\end{array}$ & $\begin{array}{c}22 \% \\
(138 / 629)\end{array}$ & & $\begin{array}{c}44 \% \\
(386 / 877)\end{array}$ & $\begin{array}{c}85 \% \\
(138 / 163)\end{array}$ \\
\hline $\begin{array}{l}\mathrm{p} \text { (non- } \\
\text { inferiority) }\end{array}$ & $<0.001$ & $<0.001$ & & $<0.001$ & $<0.001$ \\
\hline p-value (superior) & 0.03 & 0.45 & & 0.32 & 0.04 \\
\hline \multicolumn{6}{|c|}{ B. For GG $\geq 3$ ( $19 \%$ of cases $)$} \\
\hline Modality & Sensitivity & Specificity & & PPV & NPV \\
\hline mpMRI & $\begin{array}{c}94 \% \\
(145 / 154) \\
\end{array}$ & $\begin{array}{c}17 \% \\
(112 / 642) \\
\end{array}$ & & $\begin{array}{c}21 \% \\
(145 / 675) \\
\end{array}$ & $\begin{array}{c}93 \% \\
(112 / 121) \\
\end{array}$ \\
\hline Micro-ultrasound & $\begin{array}{c}93 \% \\
(144-154) \\
\end{array}$ & $\begin{array}{c}21 \% \\
(136 / 642)\end{array}$ & & $\begin{array}{c}22 \% \\
(144 / 657)\end{array}$ & $\begin{array}{c}93 \% \\
(136 / 146)\end{array}$ \\
\hline $\mathrm{p}$ (non-inferiority) & $<0.001$ & $<0.001$ & & $<0.001$ & $<0.001$ \\
\hline $\mathrm{p}$ (superior) & 0.59 & 0.06 & & 0.43 & 0.41 \\
\hline \multicolumn{6}{|c|}{ C. PPV by PI-RADS and PRI-MUS score } \\
\hline & 3 & 4 & 5 & Unknown & 4 or 5 \\
\hline MRI PI-RADS & $14 \%$ & $38 \%$ & $62 \%$ & $49 \%$ & $40 \%$ \\
\hline U/S PRI-MUS & $19 \%$ & $39 \%$ & $61 \%$ & $46 \%$ & $42 \%$ \\
\hline
\end{tabular}

GG: Gleason grade; mpMRI: multiparametric magnetic resonance imaging; NPV: negative predictive value; PPV: positive predictive value; US: ultrasound. 


\begin{tabular}{|l|c|c|c|c|c|c|c|c|c|}
\hline Table 3. Detailed results per site & \multicolumn{7}{|c|}{ Micro-ultrasound } & n \\
\hline \multirow{2}{*}{ Site } & $\begin{array}{c}\text { Multiparametric MRI } \\
\text { positive }\end{array}$ & $\begin{array}{c}\text { True } \\
\text { negative }\end{array}$ & $\begin{array}{c}\text { False } \\
\text { positive }\end{array}$ & $\begin{array}{c}\text { False } \\
\text { negative }\end{array}$ & $\begin{array}{c}\text { True } \\
\text { positive }\end{array}$ & $\begin{array}{c}\text { True } \\
\text { negative }\end{array}$ & $\begin{array}{c}\text { False } \\
\text { positive }\end{array}$ & $\begin{array}{c}\text { False } \\
\text { negative }\end{array}$ & \\
\hline A & 70 & 46 & 64 & 14 & 84 & 13 & 97 & 0 & 194 \\
\hline B & 3 & 1 & 5 & 0 & 3 & 0 & 6 & 0 & 9 \\
\hline C & 97 & 22 & 163 & 10 & 97 & 44 & 141 & 10 & 292 \\
\hline D & 9 & 7 & 1 & 2 & 10 & 2 & 6 & 1 & 19 \\
\hline E & 76 & 5 & 76 & 2 & 74 & 12 & 69 & 4 & 159 \\
\hline F & 20 & 9 & 20 & 2 & 22 & 5 & 24 & 0 & 51 \\
\hline G & 24 & 13 & 38 & 2 & 25 & 9 & 42 & 1 & 77 \\
\hline H & 29 & 27 & 53 & 7 & 31 & 24 & 56 & 5 & 116 \\
\hline I & 19 & 3 & 25 & 0 & 17 & 8 & 20 & 2 & 47 \\
\hline J & 21 & 1 & 40 & 0 & 19 & 21 & 20 & 2 & 62 \\
\hline K & 3 & 2 & 8 & 1 & 4 & 0 & 10 & 0 & 14 \\
\hline Total & $\mathbf{3 7 1}$ & $\mathbf{1 3 6}$ & $\mathbf{4 9 3}$ & $\mathbf{4 0}$ & $\mathbf{3 8 6}$ & $\mathbf{1 3 8}$ & $\mathbf{4 9 1}$ & $\mathbf{2 5}$ & $\mathbf{1 0 4 0}$ \\
\hline
\end{tabular}

While clear site-level variability is seen on targeting percentage and accuracy, only 3 sites (B, I, J) failed to achieve non-inferior sensitivity on their own. Aggregate results demonstrate superior sensitivity for micro-ultrasound $(\mathrm{p}=0.03)$ and non-inferior specificity $(\mathrm{p}<0.01)$. MRI: magnetic resonance imaging.

\begin{tabular}{|c|c|c|c|c|c|c|}
\hline \multicolumn{7}{|c|}{ Supplementary Table 1. Summary of registry sites with methodological variations } \\
\hline Site identifier & Clinic name & Location & $\begin{array}{l}\text { Indication } \\
\text { for Biopsy }\end{array}$ & $\begin{array}{c}\text { mpMRI } \\
\text { specifications }\end{array}$ & $\begin{array}{c}\text { mpMRI } \\
\text { targeting } \\
\text { system }\end{array}$ & $\begin{array}{c}\text { Blinded or } \\
\text { unblinded } \\
\text { MRI }\end{array}$ \\
\hline A & $\begin{array}{c}\text { Urología } \\
\text { Clínica, } \\
\text { Clínica IMQ } \\
\text { Zorrotzaurre }\end{array}$ & $\begin{array}{l}\text { Bilbao, } \\
\text { Spain }\end{array}$ & $\begin{array}{c}\text { Clinical } \\
\text { variables, } \\
\text { including } \\
\text { MRI }\end{array}$ & $\begin{array}{l}\text { b-value } \geq 1400 \\
\text { no ERC }\end{array}$ & $\begin{array}{l}\text { Cognitive } \\
\text { fusion } \\
\text { (micro-US- } \\
\text { guided) }\end{array}$ & Unblinded \\
\hline B & $\begin{array}{c}\text { Urology of } \\
\text { Virginia, } \\
\text { Eastern } \\
\text { Virginia } \\
\text { Medical } \\
\text { School }\end{array}$ & $\begin{array}{c}\text { Virginia } \\
\text { Beach, U.S }\end{array}$ & $\begin{array}{c}\text { Clinical } \\
\text { variables, } \\
\text { including } \\
\text { MRI }\end{array}$ & $\begin{array}{c}\text { 3T Toshiba } \\
\text { Titan no ERC } \\
\text { b-value } 2000\end{array}$ & $\begin{array}{l}\text { Cognitive } \\
\text { fusion } \\
\text { (micro-US- } \\
\text { guided) }\end{array}$ & Blinded \\
\hline $\mathrm{C}$ & $\begin{array}{c}\text { Instituto } \\
\text { Clinico } \\
\text { Humanitas }\end{array}$ & $\begin{array}{l}\text { Rozzano, } \\
\text { Italy }\end{array}$ & $\begin{array}{l}\text { Suspicious } \\
\text { mpMRI only }\end{array}$ & $1.5 \mathrm{~T}$ and $3 \mathrm{~T}$ & $\begin{array}{l}\text { Biojet } \\
\text { robotic } \\
\text { fusion }\end{array}$ & Blinded \\
\hline
\end{tabular}




\begin{tabular}{|c|c|c|c|c|c|c|}
\hline $\mathrm{D}$ & $\begin{array}{c}\text { Glickman } \\
\text { Urological } \\
\text { Institute, } \\
\text { Cleveland } \\
\text { Clinic }\end{array}$ & $\begin{array}{l}\text { Cleveland, } \\
\text { U.S. }\end{array}$ & $\begin{array}{c}\text { Clinical } \\
\text { variables, } \\
\text { including } \\
\text { MRI }\end{array}$ & $\begin{array}{c}\text { 3T Siemens } \\
\text { Skyra no ERC }\end{array}$ & $\begin{array}{l}\text { Uronav } \\
\text { software } \\
\text { fusion }\end{array}$ & Unblinded \\
\hline E & $\begin{array}{c}\text { Charité } \\
\text { Universitätsme } \\
\text { dizin }\end{array}$ & $\begin{array}{l}\text { Berlin, } \\
\text { Germany }\end{array}$ & $\begin{array}{c}\text { Clinical } \\
\text { variables, } \\
\text { including } \\
\text { MRI }\end{array}$ & $\begin{array}{l}\text { 3T with pelvic } \\
\text { phased array } \\
\text { coil no ERC }\end{array}$ & $\begin{array}{l}\text { Hitachi } \\
\text { software } \\
\text { fusion }\end{array}$ & Unblinded \\
\hline $\mathrm{F}$ & $\begin{array}{c}\text { Groupe } \\
\text { Urologie } \\
\text { Saint-Augustin }\end{array}$ & $\begin{array}{l}\text { Bordeaux, } \\
\text { France }\end{array}$ & $\begin{array}{c}\text { Clinical } \\
\text { variables, } \\
\text { including } \\
\text { MRI }\end{array}$ & $1.5 \mathrm{~T}$ and $3 \mathrm{~T}$ & $\begin{array}{l}\text { Cognitive } \\
\text { fusion } \\
\text { (micro-US- } \\
\text { guided) }\end{array}$ & Unblinded \\
\hline G & $\begin{array}{c}\text { Sunnybrook } \\
\text { Hospital }\end{array}$ & $\begin{array}{l}\text { Toronto, } \\
\text { Canada }\end{array}$ & $\begin{array}{c}\text { Clinical } \\
\text { variables, } \\
\text { including } \\
\text { MRI }\end{array}$ & $\begin{array}{c}\text { Siemens and } \\
\text { Phillips 3T, no } \\
\text { ERC }\end{array}$ & $\begin{array}{l}\text { Cognitive } \\
\text { fusion } \\
\text { (micro-US- } \\
\text { guided) }\end{array}$ & Unblinded \\
\hline $\mathrm{H}$ & $\begin{array}{l}\text { Polyclinique } \\
\text { Reims- } \\
\text { Bezannes }\end{array}$ & $\begin{array}{l}\text { Bezannes, } \\
\text { France }\end{array}$ & $\begin{array}{c}\text { Clinical } \\
\text { variables, } \\
\text { including } \\
\text { MRI }\end{array}$ & $1.5 \mathrm{~T}$ and $3 \mathrm{~T}$ & $\begin{array}{l}\text { Cognitive } \\
\text { fusion } \\
\text { (micro-US- } \\
\text { guided) }\end{array}$ & Unblinded \\
\hline I & $\begin{array}{c}\text { Institut } \\
\text { Mutualiste } \\
\text { Montsouris }\end{array}$ & $\begin{array}{l}\text { Paris, } \\
\text { France }\end{array}$ & $\begin{array}{c}\text { Clinical } \\
\text { variables, } \\
\text { including } \\
\text { MRI }\end{array}$ & $\begin{array}{c}3 \mathrm{~T} \\
\text { no ERC }\end{array}$ & $\begin{array}{l}\text { Cognitive } \\
\text { fusion } \\
\text { (micro-US- } \\
\text { guided) }\end{array}$ & Unblinded \\
\hline $\mathrm{J}$ & $\begin{array}{l}\text { Ordenskliniku } \\
\mathrm{m}\end{array}$ & $\begin{array}{l}\text { Linz, } \\
\text { Austria }\end{array}$ & $\begin{array}{c}\text { Clinical } \\
\text { variables, } \\
\text { including } \\
\text { MRI }\end{array}$ & $1.5 \mathrm{~T}$ and $3 \mathrm{~T}$ & $\begin{array}{l}\text { FusionVu } \\
\text { micro-US- } \\
\text { guided }\end{array}$ & Unblinded \\
\hline K & $\begin{array}{c}\text { Carolina } \\
\text { Urologic } \\
\text { Research } \\
\text { Center }\end{array}$ & $\begin{array}{c}\text { Myrtle } \\
\text { Beach, U.S. }\end{array}$ & $\begin{array}{c}\text { Clinical } \\
\text { variables, } \\
\text { including } \\
\text { MRI }\end{array}$ & $1.5 \mathrm{~T}$ and $3 \mathrm{~T}$ & $\begin{array}{l}\text { Cognitive } \\
\text { fusion } \\
\text { (micro-US- } \\
\text { guided) }\end{array}$ & Unblinded \\
\hline
\end{tabular}

MRI: magnetic resonance imaging; US: ultrasound. 